University of Nebraska - Lincoln

DigitalCommons@University of Nebraska - Lincoln

2006

\title{
Spring Census of Mid-Continent Sandhill Cranes Using Aerial Infrared Videography
}

\author{
Paul Kinzel \\ U.S. Geological Survey \\ Jonathan Nelson \\ U.S. Geological Survey \\ Randolph Parker \\ U.S. Geological Survey \\ Lawrence Davis \\ U.S. Geological Survey
}

Follow this and additional works at: https://digitalcommons.unl.edu/usgsstaffpub

Part of the Earth Sciences Commons

Kinzel, Paul; Nelson, Jonathan; Parker, Randolph; and Davis, Lawrence, "Spring Census of Mid-Continent Sandhill Cranes Using Aerial Infrared Videography" (2006). USGS Staff -- Published Research. 76.

https://digitalcommons.unl.edu/usgsstaffpub/76

This Article is brought to you for free and open access by the US Geological Survey at DigitalCommons@University of Nebraska - Lincoln. It has been accepted for inclusion in USGS Staff -- Published Research by an authorized administrator of DigitalCommons@University of Nebraska - Lincoln. 


\title{
Spring Census of Mid-Continent Sandhill Cranes Using Aerial Infrared Videography
}

\author{
PAUL J. KINZEL, ${ }^{1}$ U.S. Geological Survey, Denver Federal Center, Lakewood, CO 80225, USA \\ JONATHAN M. NELSON, U.S. Geological Survey, Denver Federal Center, Lakewood, CO 80225, USA \\ RANDOLPH S. PARKER, U.S. Geological Survey, Denver Federal Center, Lakewood, CO 80225, USA \\ LAWRENCE R. DAVIS, Davis Aviation, Kent, OH 44240, USA
}

\begin{abstract}
Aerial infrared videography was used to map spatial distributions of nocturnal sandhill crane (Grus canadensis) flocks and determine crane densities within roosts as an alternative to the currently used diurnal photo-corrected ocular transect method to estimate the size of the midcontinental population. The densities determined from samples taken over the course of a night show variability. Densities measured early in the night (2100 to $2300 \mathrm{hrs}$ ) were generally lower than those measured in the time period after midnight and up until cranes prepared to depart their roosts before sunrise. This suggests that cranes may be more active early in the night and possibly still settling into their roosts at this time. For this reason, densities and areas measured later at night and into the early morning were used to estimate population size. Our methods estimated that the annual crane populations along the central Platte River in Nebraska were higher than estimates from the ocular transect method; however both methods showed a similar trend with time. Our population size estimates likely were higher because our methodology provided synoptic imagery of crane roosts along the entire study reach when all cranes had returned to the river, and the nocturnal densities were higher than previous estimates using observations from late evening or early morning. In addition to providing a tool for estimating annual population size, infrared videography can be utilized over time to identify spatial changes in the roosting patterns that may occur as a result of riverine management activities. (JOURNAL OF WILDLIFE MANAGEMENT 70(1):70-77; 2006)
\end{abstract}

\section{Key words}

Grus canadensis, infrared, Mid-continent, Nebraska, Platte River, populations, remote sensing, roosting, sandhill crane, videography.

The annual spring migration of mid-continent sandhill cranes through Nebraska has been called one of the greatest ecological spectacles in North America. From March through early April cranes make their way northward from their wintering grounds in Texas and Mexico to stage in the Platte and North Platte River Valleys (Krapu et al. 1984). During the day cranes are distributed in cornfields and wetland meadows where they feed and amass body fat for their northern migration (Krapu et al. 1985). At dusk the cranes return to the North Platte and Platte Rivers to roost on submerged sandbars.

The maximum number of sandhill cranes staging in the North Platte and Platte River Valleys, collectively referred to as the Central Platte Valley (CPV) by the U.S. Fish and Wildlife Service (USFWS), currently ranges between $306,000-541,000$ based on data from 1979 and 1980 (U.S. Fish and Wildlife Service 1981). The last diurnal high-altitude vertical photographic survey conducted in 1982 along the CPV counted 490,000 cranes (Benning and Johnson 1987). The large concentration of sandhill cranes in the CPV represents $>95 \%$ of the mid-continent population (Sharp et al. 2002). Therefore, the USFWS has, since 1982, conducted an annual diurnal photo-corrected ocular survey along the CPV (Benning and Johnson 1987, Solberg 2004). This survey is used in conjunction with concurrent counts on spring staging areas from the Central Flyway states of Nebraska, Kansas, and Texas to monitor the trend in the size of the mid-continent population. These coordinated surveys provide the metric that is compared against the population goal (343,000-465,000 cranes; Sharp et al. 2002). With the exception of Nebraska, sandhill cranes are hunted in all of the states in the Central Flyway.

${ }^{1}$ E-mail: pjkinzel@usgs.gov
Over the last century, development of upstream water resources has altered the historical regime of water and sediment inputs to the central Platte River, transforming a once wide, braided river into a narrower, channelized, and vegetated river (Williams 1978, U.S. Fish and Wildlife Service 1981, Eschner et al. 1983, O’Brien and Currier 1987). These changes have altered the roosting habitat used by cranes (Krapu et al. 1982, Faanes and LeValley 1993). A habitat recovery program is currently proposed for the central Platte River. Management of lands acquired by the program will partially be aimed at restoring riverine roosting habitat that has been lost through vegetation encroachment and channel narrowing. Possible management alternatives include vegetation modification along riparian and in-channel areas, restoration of wetland meadow habitats, and augmentation and manipulation of stream flow for channel maintenance. Evaluating the effect of these strategies on cranes requires a detailed understanding of current roosting patterns and the ability to efficiently monitor the crane population along the central Platte River.

There is a long history of efforts to census sandhill cranes in Nebraska. The first survey, called the ocular cruise, was initiated in 1957 (Wheeler and Lewis 1972). In 1972, the ocular cruise was modified to include predawn counts along roosting areas in the Platte River Valley. The census technique consisted of observers in an aircraft counting both the cranes roosting in the river and those within a $1.6-\mathrm{km}$ strip on either side between daybreak and one hour after sunrise (Lewis 1978). Lewis (1978) believed that the ocular cruise underestimated the number of cranes based on the large annual variations in the counts and deemed it unable to detect $\pm 25 \%$ changes in annual population size. In 1979, the ocular transect method was adopted to increase the spatial extent 
of the survey by traversing all known foraging areas in the CPV adjacent to the North Platte and Platte Rivers (Ferguson et al. 1979). In 1982, the ocular transect method was altered (Benning and Johnson 1987) by standardizing the time of the day and year that the survey was conducted (between 0800 and 1600 hours on the fourth Tuesday in Mar). The random starting points for sampling from the transects population was replaced by a single set of 54 transects that are sampled annually. The ability of pilot and observer to accurately count the cranes on a transect was determined by using a third individual to subsample the ocularly counted crane flocks with 35-mm oblique photography. The photographs allow the computation of observer-specific correction factors used to adjust the ocular count (Benning and Johnson 1987, Solberg 2004).

Some investigators have obtained images of roosting flocks of sandhill cranes on the Platte River using near-dawn aerial photographs (Latka et al. 1986, Norling et al. 1990) or neardawn oblique videography (Davis 2001). Roosting cranes assemble into flocks for protection from predation. This behavior provides a unique opportunity to census the birds efficiently because roosting cranes are less dispersed than when they are on foraging areas. However, because cranes arrive to their roosts after sunset and depart prior to sunrise, nocturnal imaging techniques are needed to completely census the population.

Infrared detectors from military sources have been used to obtain nocturnal images of sandhill cranes roosting on the Platte River (Munro and Lewis 1976, Pucherelli 1985, 1988, Sidle et al. 1993). These investigators have demonstrated that sufficient thermal contrast or difference in emissivity exists between sandhill cranes and their roost sites. Because of the insulating properties of their feathers, cranes emit less thermal radiation than the surrounding water and are recognizable as small dots on an infrared image. Although infrared technology has been available for monitoring the annual population of sandhill cranes in the CPV for some time, its repeated application has been limited by a variety of factors including cost, weather, navigation, access to equipment, and other logistics.

We used an aerial infrared videography technique to census the mid-continental sandhill crane population during their annual spring stopover in the central Platte River. Our objectives were to map and evaluate the annual variation in roost locations, evaluate temporal and spatial variation in crane densities at roost sites, and compare population estimates gained in the central Platte River using infrared videography with the ocular photo-corrected diurnal count currently in use. We also address the reliability and cost effectiveness of infrared videography for annually estimating the size of the mid-continent population of sandhill cranes.

\section{Methods}

\section{Study Area}

We conducted infrared surveys along the 130-km-long reach of the Platte River between Lexington and Grand Island, Nebraska (Fig. 1). This reach of the central Platte River is referred to as the Big Bend and includes 2 of the 3 major spring staging areas in Nebraska (Krapu et al. 1982). The third staging area is located near Hershey on the North Platte River. The USFWS annual ocular photo-corrected survey is conducted in both the Platte and the North Platte River Valleys (CPV) and includes all 3 staging areas.

\section{Infrared Videography}

We used a commercial aerial thermal-imaging contractor (Davis Aviation, Kent, Ohio) to image the central Platte River for 5 nights in 2000, 3 nights in 2001, 3 nights in 2002 and 3 nights in 2003 from a Cessna 182 aircraft using a Mitsubishi IR-M600 Thermal Imager (Mitsubishi, Tokyo, Japan). Infrared images were displayed to the pilot and camera operator on a video monitor for real-time viewing while simultaneously archived using a digital video recorder (Sony, Tokyo, Japan). The operator, via a remotecontrol unit, could adjust the gain or strength of signal of the thermal imager to optimize image contrast. The thermal-imaging camera was mounted vertically on a turret fastened above a hole in the floor of the aircraft fuselage. The majority of the imagery used to map the spatial distribution of cranes was collected between 2400 and 0200 hours to ensure that all staging cranes had returned to their roosts. Additional imagery was collected during various times throughout the night to compute the densities of the
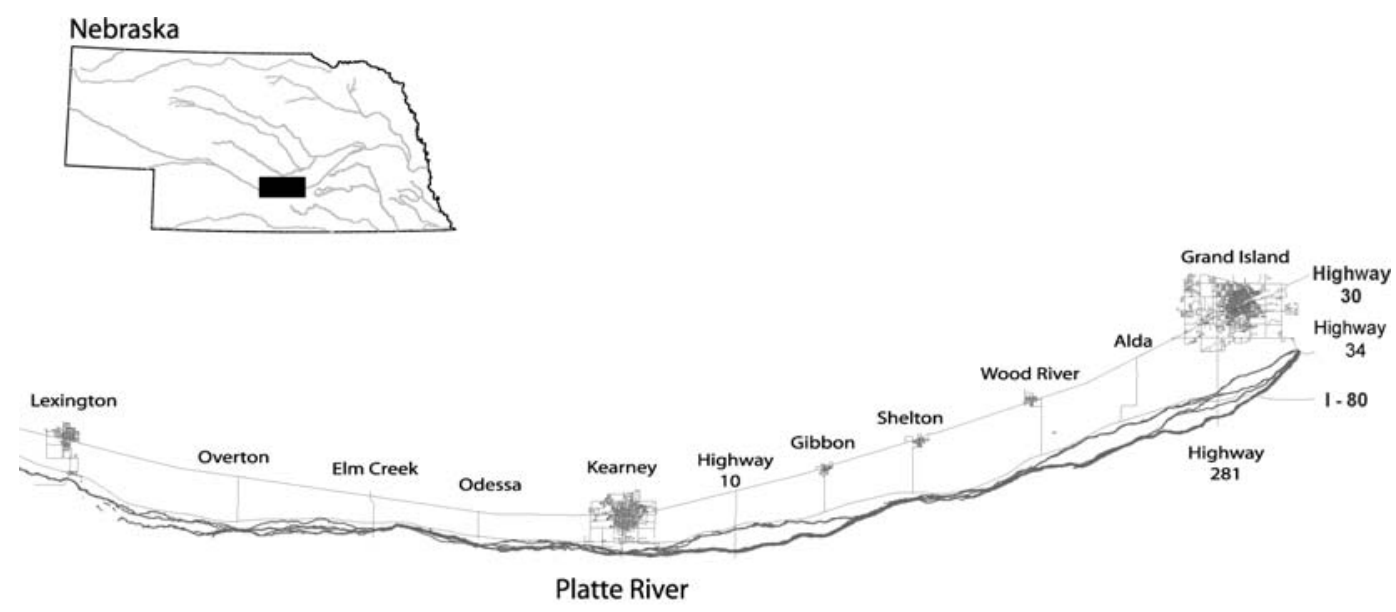

$0 \quad 10 \quad 20 \mathrm{~km}$

Figure 1. Infrared survey reach and bridge segments along the central Platte River, Nebraska. 
roosting birds. We also made nocturnal ground observations of crane roosts with the infrared camera from a riverside photo-blind in 2000 and from a 12-m observation tower in 2001.

The thermal imager had a platinum silicide Schottky-Barrier infrared detector with 512 by 512 pixels. The infrared detector could detect infrared radiation in the 3- to 5-micron wavelength. The camera used an infrared, polarized $550 \mathrm{~mm}$ F1.2 lens. Using this lens, the noise equivalent temperature differential (NETD) was $0.08^{\circ} \mathrm{C}$ for a black body at $27^{\circ} \mathrm{C}$. The field of view of the detector using an $550 \mathrm{~mm}$ lens as reported by the manufacturer was $14^{\circ}$ horizontal by $11^{\circ}$ in the vertical. From a high-altitude vantage point crane roosts could be discerned in a "white hot" thermal video image as gray areas silhouetted against the higher temperature river water, which appeared as a lighter background (Fig. 2A). Exposed sandbars and vegetated islands were easily distinguished, as these features also were less emissive than the river water. Thermal contrast in the water was observed in an infrared image, with the smaller contrast being the result of turbulence generated from fluid shear around sandbars and islands; larger contrast could be observed where mixing occurs between channels with different water temperatures.

Objectives of the study required imagery that both displayed the distribution of sandhill crane roosts and resolved individual birds. An altitude of approximately $1,200 \mathrm{~m}$ produced a field of view large enough to capture an image of the entire width of river channel and both banks, through most of the reach surveyed.
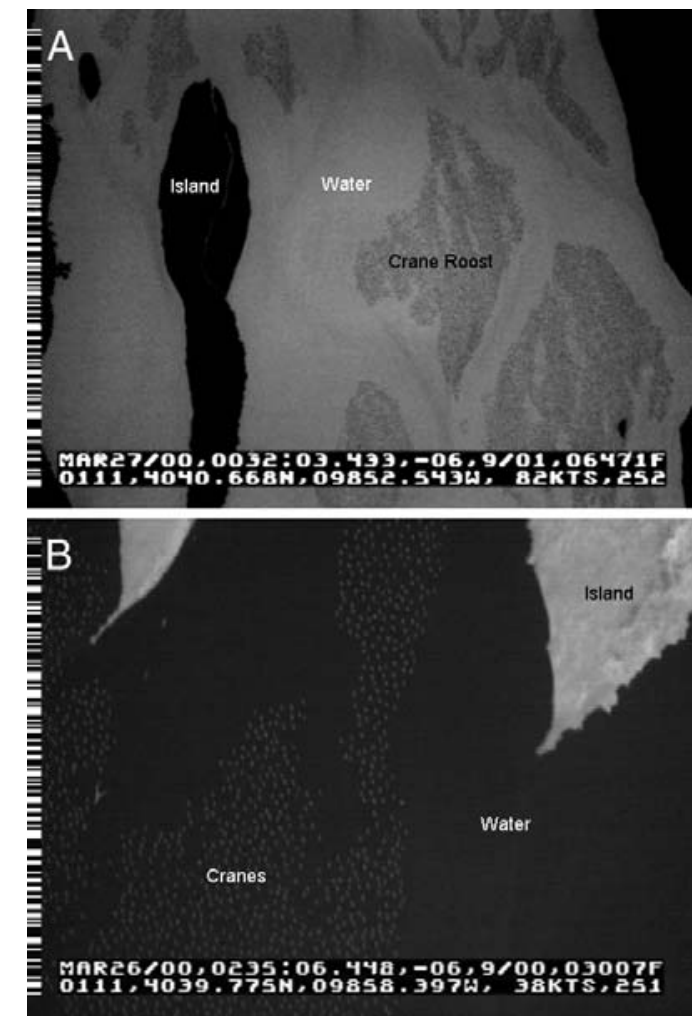

Figure 2. (A) Infrared video image of sandhill crane roosting flocks on the Platte River, Nebraska. Altitude is approximately 1200 meters above the river channel. Image is "white hot"-_darker colors represent cooler temperatures or less thermal emissivity. (B) Infrared video image of sandhill cranes roosting on the Platte River, Nebraska. Altitude is approximately 300 meters above the river channel. Image is "black hot"-lighter colors represent cooler temperatures or less thermal emissivity.
However, while roosting flocks could be resolved at this altitude, individual birds could not. After some experimentation, we used an altitude of approximately $300 \mathrm{~m}$ to obtain the images needed to count individual birds and compute densities within roosts (Fig. 2B).

\section{Image Processing}

The imagery from the flights was stored on digital videotape (Sony). The date, time, altitude, latitude, longitude, ground speed and course were overlain on the bottom of each video image frame (Fig. 2). This information also was encoded along the left side of the video image and during playback was used in conjunction with a video decoder (Vodaka, Lottsburg, Virginia) to output a National Marine Electronics Association (NMEA) global positioning system data string. Mapping software capable of plotting the NMEA string was used to track and trace the approximate position of the aircraft over digital orthophotographs of the study area. The video was streamed from the digital video player (Sony) into a personal computer through an Institute of Electrical and Electronic Engineers (IEEE) 1394, "Fire Wire," connection. Individual video frames were selected and captured using a software package for digital video editing (Ulead Systems, Taipei, Taiwan). The video images were then imported into a Geographical Information System (GIS; Enviromental Systems Research Institute, Redlands, California) and registered or georeferenced to a series of 1998 1:24,000-scale color infrared orthophotographs of the central Platte River used as basemaps. Easily identifiable feature analogs, such as trees or permanent island points, were used in the registration process to properly scale and rotate the video images taken from the high-altitude vantage point where both banks were clearly visible in the image. This technique permitted successive video images to be placed alongside one another along river reaches where roost sites were detected. The perimeter of each roost site was then carefully digitized to create a polygon within the GIS. These polygons formed a digital coverage of correctly sized and oriented roost sites. We used the GIS software to compute the areas of these polygons within the 11 bridge segments from Lexington to Grand Island for each year surveyed.

Due to the length of the study reach and experimentation with various altitudes, rectified high-altitude images from the nights of 26 and 27 March 2000 were required to map the spatial distribution of roosts from Lexington to Grand Island, Nebraska, during the first year of data collection. On the nights of $25 \mathrm{March}$ 2001, 26 March 2002, and 24 March 2003, a single night's series of images was sufficient to cover the entire study area. The images obtained from our high-altitude flights over the river channel overlapped the banks and islands sufficiently to allow this imagery to be georeferenced. However, the altitude of these flights did not permit resolution of individual birds. Low-altitude flights, although capable of resolving individual cranes, were more difficult to georeference because of the smaller field of view and lack of suitable registration points over the open river channel. It was possible, however, to correlate low-altitude imagery with high-altitude imagery flown on the same night. Assuming that the size of the roosts and numbers of birds within the roost did not change significantly between the high and low-altitude passes, the area of the roost could be determined from a registered high- 
altitude pass image and the count could be performed on an image of the same roost area collected during a low-altitude pass. This technique was applied in the 2000 survey over 4 nights using 40 roosts located between the Highway 10 and Gibbon bridges. However, this technique was limited to smaller roosts because large roosts exceeded the field of view of the camera at low altitude. To apply this technique along the entire survey, both high-altitude and low-altitude imagery had to be conducted over the same night of flying. The time required to complete both surveys during 1 night was prohibitive. Alternatively, during the 2001, 2002, and 2003 flights we used a radar altimeter to measure the elevation of the aircraft above the water and thus camera elevation above the roosting birds. The elevation was used with the camera lens geometry to compute the horizontal and vertical dimensions of the low-altitude video image. Once scaled, the area of the imaged roost was digitized and the number of individuals counted within that circumscribed polygon. The spatial density of roosting cranes (number of cranes per square meter of roost) was computed by dividing the number of cranes counted by the area of the digitized polygon. This technique yielded spatial densities that were comparable with the range of those measured in 2000 from registered images.

In 2001, 2002, and 2003, 5 density samples were collected in each of 6 bridge segments between Lexington and Grand Island between 2300 and 0200 hours to calculate a mean spatial density. The number of cranes roosting in the central Platte River during the 2000, 2001, 2002, and 2003 survey dates was estimated by multiplying the roosting areas (Table 1 ) with the mean density computed for that year. We also computed the $95 \%$ confidence intervals for the mean density and multiplied these by the corresponding areas to illustrate the effect of the variability of crane densities upon the annual population estimates.

We evaluated simple image-processing techniques to automate the counting of individual cranes on low-altitude images. We used an iterative procedure to select the pixel threshold that best isolated and contrasted crane pixels from the background water pixel values. Other larger contrasting objects in the image, such as islands, were eliminated from the automated count by setting the upper limit on the pixel size. Although this technique seemed attractive initially, it became apparent that various factors influenced the quality of individual video images and thus the accuracy of this counting procedure. In some images, due to high airspeed, cranes were indistinct from one another such that the thermal signature emitted by 1 bird intersected the signature from an adjacent bird. The overlapping of the signatures on these images made isolation of individuals using the threshold procedure on these images problematic. The automated procedure was evaluated against a small sample of manual counts made from the images. In the majority of cases, the threshold technique underestimated the manual count, so we used manual counts to compute the densities.

The USFWS ocular photo-corrected survey provides an estimate of the total number of cranes in the CPV. Estimates using the photo-corrected ocular surveys in the central Platte River were required for comparison to the estimates from the infrared videography surveys. The annual ocular photo-corrected CPV surveys were recomputed using only the 44 transects sampled in
Table 1. Sandhill crane roost area along the central Platte River categorized by bridge segment for each year surveyed.

\begin{tabular}{lrrrr}
\hline & \multicolumn{4}{c}{ Roost area $\mathbf{( m}^{\mathbf{2}} \mathbf{~}$} \\
\cline { 2 - 5 } \multicolumn{1}{c}{ Bridge segment } & \multicolumn{1}{c}{$\mathbf{2 0 0 0}$} & $\mathbf{2 0 0 1}$ & $\mathbf{2 0 0 2}$ & \multicolumn{1}{c}{$\mathbf{2 0 0 3}$} \\
\hline Lexington - Overton & 2,455 & 23,527 & 245 & 10,995 \\
Overton - Elm Creek & 5,327 & 5,812 & 9,591 & 6,187 \\
Elm Creek - Odessa & 49,875 & 38,957 & 26,957 & 56,094 \\
Odessa - Kearney & 12,671 & 18,823 & 19,937 & 19,806 \\
Kearney - Highway 10 & 53,718 & 30,615 & 52,327 & 54,522 \\
Highway 10 - Gibbon & 246,042 & 181,437 & 171,221 & 124,364 \\
Gibbon - Shelton & 78,405 & 48,702 & 78,396 & 91,750 \\
Shelton - Wood River & 114,021 & 96,847 & 106,175 & 164,068 \\
Wood River - Alda & 120,755 & 106,030 & 110,671 & 109,312 \\
Alda - Highway 281 & 138,975 & 94,208 & 94,307 & 88,223 \\
Highway 281 - Highway 34 & 55,076 & 92,334 & 115,451 & 85,625 \\
Total & 877,320 & 737,292 & 785,278 & 810,946 \\
\hline
\end{tabular}

the central Platte River to give an estimate of the number of cranes in this staging area (J. Solberg, U.S. Fish and Wildlife Service, unpublished data).

\section{Results}

\section{Area and Distribution of Roosts}

Crane flocks were not homogeneously distributed along the study reach (Table 1). The majority of cranes were located east of Kearney, Nebraska. In 3 of the 4 years surveyed, $>20 \%$ of the total sandhill crane roost area computed from the videography was between the Highway 10 and Gibbon bridges. The percentages of roosting areas distributed among the bridge segments varied in the 4 annual surveys. The percentage of roost area digitized between the Highway 10 and Gibbon bridges and the Alda and Highway 281 bridges decreased each year from 2000 to 2003. During the same period of time the percentage of roost area increased each year in the Shelton to Wood River segment. The greatest range in the percentages of roosting areas over the 4 years was observed in the river reaches between the Highway 10 and Gibbon bridges and the Highway 281 and Highway 34 bridges. The smallest range in percentages was found in the Overton to Elm Creek segment and the Wood River to Alda segment.

\section{Densities of Roosting Sandhill Cranes}

Surveys conducted in 2002 suggested that crane density varied during the night. The density was highest between 0100 and 0500 hours (Fig. 3). During 2001, 2002 and 2003 crane densities were somewhat greater in the western end of the study reach than in the eastern end (Fig. 4). The mean density of cranes in 40 roosts imaged in 2000 over 4 nights between the Highway 10 and Gibbon bridges was 0.63 cranes $/ \mathrm{m}^{2}$ (SE 0.021). The mean densities computed in 2001, 2002, and 2003 were calculated using 30 scaled images, 5 taken in each of 6 sample sites, between the Overton and Highway 34 bridges. The mean density was 0.66 cranes $/ \mathrm{m}^{2}(\mathrm{SE}=0.018)$ in $2001,0.62$ cranes $/ \mathrm{m}^{2}(\mathrm{SE}=0.018)$ in 2002, and 0.64 cranes $/ \mathrm{m}^{2}(\mathrm{SE}=0.016)$ in 2003 .

\section{Population Estimates from Infrared Videography and Diurnal Surveys}

Using the roost areas digitized from the infrared imagery and the mean densities calculated above, approximately 552,000 $\pm 38,000$ 


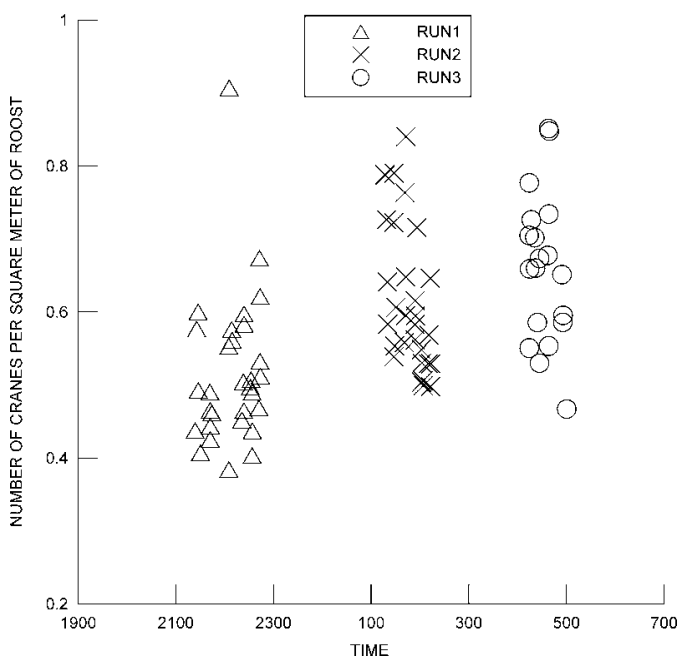

Figure 3. Spatial density of roosting sandhill cranes along the Platte River, Nebraska, at various times throughout the night of 29 Mar 2002 into 30 Mar 2002.

cranes were estimated in $2000,488,000 \pm 26,000$ in $2001,486,000$ $\pm 28,000$ in 2002 and $516,000 \pm 25,000$ in 2003 . The USFWS estimated 438,600 cranes in $2000,286,000$ in $2001,273,600$ in 2002 , and 264,800 in 2003. Both the USFWS ocular photocorrected survey and the aerial infrared video method gave the highest population count in 2000. Both methods also recorded a relatively large decrease in population counts from 2000 to 2001 and a decrease in population size from 2001 to 2002. However, the infrared survey method showed an increase in population from 2002 to 2003 while the ocular photo-corrected method showed a decrease (Fig. 5). The mean population estimated using the infrared survey method exceeded the mean of the ocular photo-corrected method by approximately 195,000 cranes over the 4 years sampled.

\section{Discussion}

\section{Area and Distribution of Roosts}

Other workers have described a distribution pattern of sandhill crane roosts (Pucherelli 1988; Sidle et al. 1993; Platte River Whooping Crane Maintenance Trust, unpublished data) similar to the distribution described in this paper. The location of roosts in the central Platte River has been attributed to the distribution of wide channels and the proximity of the river to wetland meadows (Faanes and LeValley 1993, Sidle et al. 1993, Davis 2001). The highest percentage of sandhill crane areas in 3 of the 4 years was found in the Highway 10 to Gibbon bridge segment. This bridge segment contains the Lillian Annette Rowe Sanctuary - a National Audubon Society sanctuary and a reach of the river where riparian and in-channel vegetation is actively managed to preserve unobstructed views for roosting cranes.

\section{Densities of Roosting Cranes}

Our estimates of spatial densities for roosting sandhill cranes are greater than those reported in studies by Pucherelli (1988) and Sidle et al. (1993). Pucherelli (1985) used thermography to estimate the roosting areas along 2 bridge segments, but because individual cranes could not be resolved in the thermography, early morning photographs were used to compute density. By overlaying sample grids on these photographs the density of cranes was

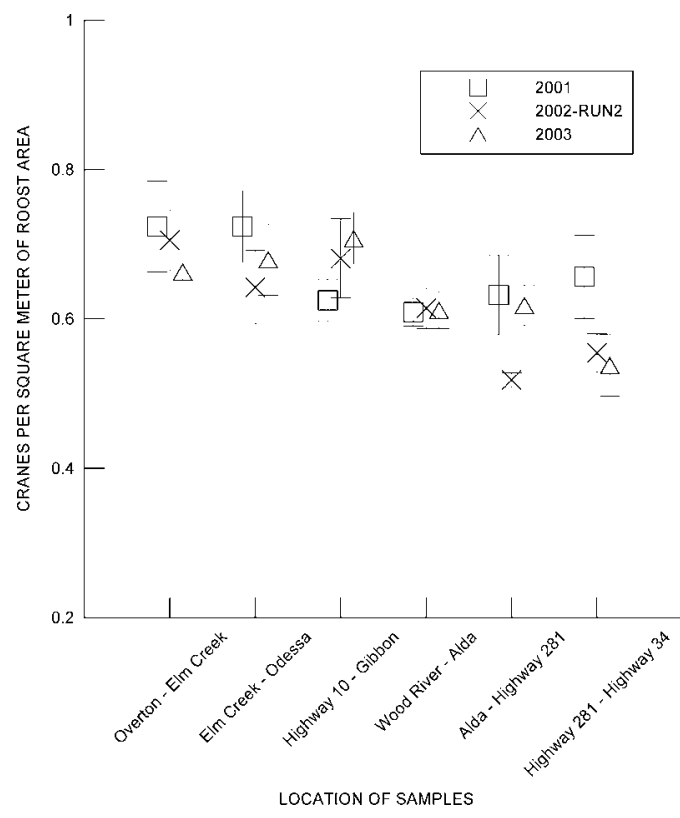

Figure 4. Spatial distribution of sandhill crane mean densities for 6 sample sites along the central Platte River, Nebraska collected in 2001, 2002 and 2003. The standard error of the mean for each sample site is shown with bars. Samples were collected between 2300 and 0500 hours.

determined to be 0.60 cranes $/ \mathrm{m}^{2}$. Pucherelli (1988) revised this number to be $0.32 \mathrm{cranes} / \mathrm{m}^{2}$ based on additional analysis of these photos in 1985 (M. Pucherelli, U.S. Bureau of Reclamation, unpublished data). Sidle et al. (1993) conducted infrared surveys over 2 nights in 1989 with the Nebraska Air National Guard's AN/AAD infrared reconnaissance system and estimated a mean density of $0.29 \mathrm{cranes} / \mathrm{m}^{2}$. However, Sidle et al. (1993) believed that, because the aircraft passed over the study site $<1$ hour after sunset, all the cranes had probably not returned to the river. Latka et al. (1986) also computed densities of roosting cranes on the Platte River from early morning photographs and calculated 0.30 0.37 cranes $/ \mathrm{m}^{2}$. Because these studies were conducted in either late evening or early morning, they could have reflected movement of cranes into or out of the roosts. Folk and Tacha (1990) estimated a maximum density of 0.53 cranes $/ \mathrm{m}^{2}$ from infrared photography of sandhill cranes on the North Platte River.

Our method to estimate population size reconciled the fact that 2 different sampling strategies were used. In 2000 the density samples were stratified on a nightly basis along a single segment of river. In 2001, 2002, and 2003 the samples were stratified into multiple segments of river over a single night. This approach assumes that the statistics of the sampled stratum do not vary significantly among stratum, so all stratum can be given equal weight and pooled together. We investigated this assumption by considering the spatially stratified sampling strategy used in 2001, 2002, and 2003. The method presented in Ferguson et al. (1979) for estimating the density and total number of cranes with the stratified ocular transect survey was adapted to the spatially stratified infrared survey. However, the infrared survey in 2001, 2002 , and 2003 only consisted of 6 of the 11 bridge segments so it must be assumed that the population is comprised of these 6 stratum. Estimates and the standard errors of density and population size for the 6 stratum using pooled data were compared 


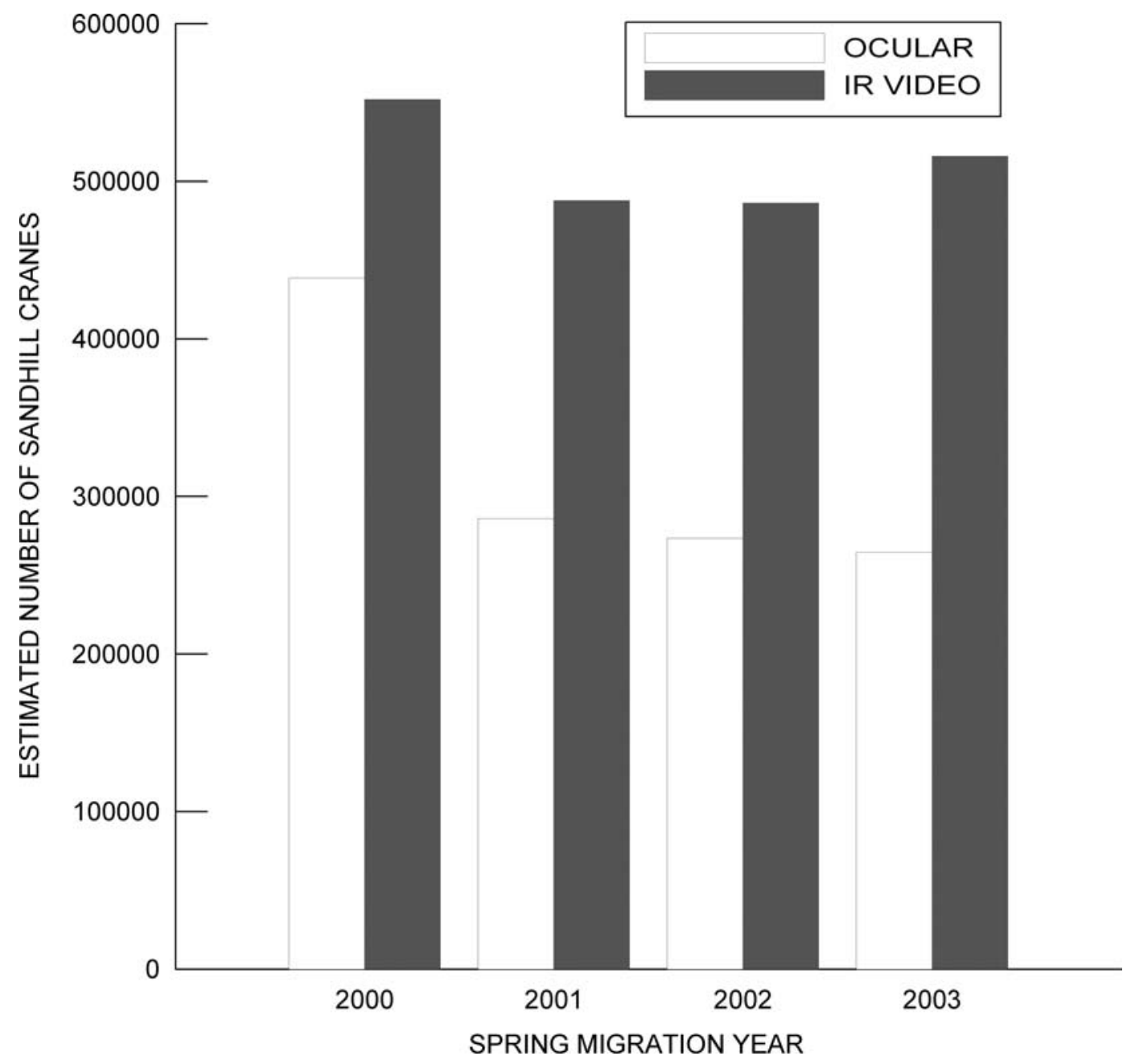

Figure 5. Sandhill crane population estimates for the central Platte River. U.S. Fish and Wildlife Service estimate from diurnal photo-corrected ocular survey. U.S. Geological Survey estimate from nocturnal infrared videography technique.

to the estimate using weighted stratified sampling. The 2 methods yielded results that differed by only a few percent.

\section{Population Estimates from Infrared Videography and Diurnal Surveys}

Because the aerial infrared videography survey and ocular photocorrected survey do not directly count cranes, they operate on 2 fundamental assumptions, that the survey sufficiently samples the spatial distribution of cranes and that the cranes are accurately estimated on the samples. The population size estimates from aerial infrared videography have potential sources of error with regard to these assumptions. A potential source of error with the first assumption is the fact that cranes can only be detected if they are standing on highly emissive backgrounds such as water. At low river discharges, cranes can roost on subaerial sandbars in the river channels. Although the majority of cranes roost in low water depths, cranes roosting on exposed sandbars are not visible from high-altitude infrared imagery and would not be counted. Therefore, depending on the river flow and the proportion of cranes roosting on subaerial sandbars, infrared counts could underestimate population size.

Another potential source of error is the fact that the resolution of the infrared camera used was not sufficient to discern between the thermal signatures of comparably sized birds at typical observation altitudes. Even when flying at relatively low altitude it is difficult to distinguish between a crane and other bird species based solely on their thermal signatures. The aerial infrared surveys were scheduled to coincide with the USFWS ocular surveys. However, at this time we also anticipated that most Canada geese (Branta canadensis) and snow geese (Chen caerulescens) had departed the central Platte River. Weekly ground surveys in 2000 and 2001 conducted both by the U.S. Geological Survey Northern Prairie Wildlife Research Center and the Platte River Whooping Crane Maintenance Trust suggested that geese numbers were low at the time of the infrared surveys (Krapu and Brandt, Platte River Whooping Crane Maintenance Trust, unpublished data). Nevertheless, other birds could have biased the area and density estimates from the infrared surveys. Determining the bias in counts of sandhill cranes and the feasibility of developing and applying correction methods requires intensive ground surveys that are spatially and temporal coincident with the infrared videography; this has not been done to date.

The annual ocular photo-corrected survey assumes that stratum include all known foraging areas. Reconnaissance outside the strata boundaries was conducted in 1978, and the survey boundaries were slightly adjusted because cranes were observed east of North Platte 
and southeast of Grand Island (Ferguson et al. 1979). The survey area was restratified in 1982 (Benning and Johnson, 1987) but has not been altered since. Cranes in flight or soaring during the ocular surveys are also not included in the ocular count. Benning and Johnson (1987) expressed concern over soaring cranes but believed soaring was minimal during their 1982 survey. Further investigation is needed to ascertain if significant numbers of cranes are present outside the strata boundaries and to evaluate what influence soaring may have on the bias of these diurnal counts.

The second assumption with regard to the ocular photocorrected survey is that both the pilot and observer are able to see and accurately count the cranes along each transect. Ferguson et al. (1979) concluded that as flock size increased the ability of observers to successfully count the cranes decreased. In 1982, a visibility correction factor (ratio of cranes counted on an oblique photograph to the number of cranes counted ocularly) was used to address this problem (Benning and Johnson 1987). This correction factor has been used to adjust the ocular count over the last 20 years. Solberg (2004) pointed out the difficulty in capturing large flocks with oblique photography and believed this negatively biased the correction factor. If the correction factor is negatively biased, the ocular survey would underestimate population size.

\section{Reliability and Cost-Effectiveness of Infrared Videography}

In 3 of the 4 years, our nocturnal infrared surveys were limited by weather conditions in late March. At these times, safety considerations caused by high wind speed grounded the aircraft. The initial cost of aerial infrared videography is high given the cost of purchasing a thermal infrared camera (US\$50,000US $\$ 100,000$ ). This service could alternatively be obtained through a contractor, as was the case in our study (approximately US $\$ 2,000$ per night of flying). The cost of image processing would include the software and hardware necessary for digital video editing in addition to roughly a few months of time for the image analysis. Automated orthorectification of infrared video imagery should be investigated as it could reduce the processing time for image registration. However, this technology would likely increase the cost of image acquisition.

\section{Management Implications}

Over the past 30 years a number of techniques have been used to estimate the annual population of sandhill cranes in the CPV. Our results indicate that the population size estimates for the central

\section{Literature Cited}

Benning, D. S., and D. H. Johnson. 1987. Recent improvements to sandhill crane surveys in Nebraska's Central Platte Valley. Pages 10-16 in J. C. Lewis, editor. Proceedings of 1985 International Crane Workshop. U.S. Fish and Wildlife Service, Grand Island, Nebraska, USA.

Davis, C. A. 2001. Nocturnal roost site selection and diurnal habitat use by sandhill cranes during spring in central Nebraska. Pages 48-56 in D. H. Ellis, editor. Proceedings of the Eighth North American Crane Workshop. North American Crane Working Group, Albuquerque, New Mexico, USA.

Eschner, T. R., R. F. Hadley, and K. D. Crowley. 1983. Hydrologic and morphologic changes in channels of the Platte River basin in Colorado, Wyoming and Nebraska: a historical perspective. U.S. Geological Survey Professional Paper 1277-A, Reston, Virginia, USA.

Faanes, C.A., and M. J. LeValley. 1993. Is the distribution of sandhill cranes on the Platte River changing? Great Plains Research 3:297-304.
Platte River in 2000, 2001, 2002, and 2003 using infrared videography were much larger than those estimated by the photocorrected ocular survey, which was originally designed to provide an index to detect population trends. In addition to providing estimates of the size of the staging population, infrared videography can supply detailed information on the spatial and temporal distribution of crane roosts, which can be used to assess the effects of habitat restoration efforts along the Platte River. If nocturnal imagery is used to estimate population size it must be performed when all the cranes have returned to the river and settled in their roosts. We believe this occurs when the density of the birds within their roosts has reached a maximum (between 2300 and 0500 hours).

The ocular photo-corrected and infrared video surveys showed similar trends in the estimated annual population size in 2 of the 3 annual intervals. This may indicate that, over the short period of comparison, the ocular photo-corrected survey is performing as it was designed for detecting annual trends in the numbers of sandhill cranes present along the central Platte River in late March. The last effort to count cranes directly was the diurnal high-altitude vertical photographic survey made over 20 years ago in the CPV; this survey indicated that the ocular counts underestimated the photographic counts by 70,000 cranes. Benning and Johnson (1987) established the operational vertical photographic survey to satisfy the goal of the Central Flyway Waterfowl Council to obtain reliable estimates of the population size every 5 years. This survey has not been repeated. The application of infrared videography technology for directly counting roosting cranes requires a survey technique that resolves the logistical and technical challenges imposed by the resolution of currently available commercial infrared detectors.

\section{Acknowledgments}

We thank J. P. Bennett and G. L. Krapu (USGS) for reviewing previous versions of this paper. S. Gyetvai and A. K. Heckman (USGS) provided support with GIS and image analysis. M. Starbuck (USGS) assisted in collecting the aerial infrared videography. The authors are appreciative of the staff and volunteers at Audubon's Rowe Sanctuary for providing access to the river reaches located within the Sanctuary property. Any use of trade, product, or firm names in this publication is for descriptive purposes only and does not imply endorsement by the U.S. Government.

Ferguson, E. L., D. S. Gilmer, D. H. Johnson, N. Lyman, and D. S. Benning. 1979. Experimental surveys of sandhill cranes in Nebraska. Pages 41-49 in J. C. Lewis, editor. Proceedings of 1978 Crane Workshop, Colorado State University, Fort Collins, USA.

Folk, M. J., and T. C. Tacha. 1990. Sandhill crane roost site characteristics in the North Platte River Valley. Journal of Wildlife Management 54:480-486.

Krapu, G. L., and D. A Brandt. In Press. Do northern nesting geese compete with sandhill cranes for waste corn in the Central Platte Valley, Nebraska? Proceedings of the Ninth North American Crane Workshop, Sacramento, California, USA.

Krapu, G. L., D. E. Facey, E. K. Fritzell, and D. H. Johnson. 1984. Habitat use by migrant sandhill cranes in Nebraska. Journal of Wildlife Management 48: 407-417. 
Krapu, G. L., G. C. Iverson, K. J. Reinecke, and C. M. Boise. 1985. Fat deposition and usage by arctic-nesting sandhill cranes during spring. Auk 102:362-368.

Krapu, G. L., K. J. Reinecke, and C. R. Frith. 1982. Sandhill cranes and the Platte River. Transactions of the North American Wildlife and Natural Resources Conference 47:542-552.

Latka, D. C., and J. W. Yahnke. 1986. Simulating the roosting habitat of sandhill cranes and validating suitability-of-use indices. Pages 19-22 in J. Verner, M. L. Morrison, and C. J. Ralph, editors. Wildlife 2000: modeling Habitat Relationships of Terrestrial Vertebrates. University of Wisconsin Press, Madison, USA.

Lewis, J. C. 1978. Spring census of sandhill cranes: factors affecting the Platte River crane census. Final Report. Accelerated program for webless migratory game birds. Oklahoma Cooperative Wildlife Research Unit, Oklahoma State University, Stillwater, USA.

Munro, R. E., and J. C. Lewis. 1976. Nighttime tests of remote sensors for census of sandhill cranes. Pages 304-308 in J. C. Lewis, editor. Proceedings of the International Crane Workshop. Oklahoma State University, Stillwater, USA.

Norling, B. S., S. H. Anderson, and W. A. Hubert. 1990. The influence of water depth, unobstructed area, and disturbance features on the selection of roost sites by sandhill cranes along the Platte River, Nebraska. Project Report, U.S. Fish and Wildlife Service, Laramie, Wyoming, USA.

O'Brien, J. S., and P. J. Currier. 1987. Platte River channel morphology and riparian vegetation changes in the Big Bend Reach and minimum streamflow criteria for channel maintenance. Platte River Trust, Grand Island, Nebraska, USA.
Pucherelli, M. J. 1985. Determining sandhill crane (Grus canadensis) roosting sites using aerial thermography and geographical information systems. U.S. Bureau of Reclamation, Denver, Colorado, USA.

Pucherelli, M. J. 1988. Measuring channel width variables of sandhill crane (Grus canadensis) roosting habitat sites along the Platte River using nighttime aerial thermography. U.S. Bureau of Reclamation, Denver, Colorado, USA.

Sharp, D. E., J. A. Dubovsky, and K. L. Kruse. 2002. Status and harvests of Mid-continent and Rocky Mountain Populations of sandhill cranes. U.S. Fish and Wildlife Service, Denver, Colorado, USA.

Sidle, J.G., H.G. Nagel, R. Clark, C. Gilbert, D. Stuart, K. Willburn, and M. Orr. 1993. Aerial infrared thermal imaging of sandhill cranes on the Platte River, Nebraska. Remote Sensing of Environment 43:333-341.

Solberg, J. 2004. Coordinated spring survey of mid-continent sandhill cranes 2003. Office of Migratory Bird Management, U.S. Fish and Wildlife Service, Jamestown, North Dakota, USA.

U.S. Fish and Wildlife Service. 1981. The Platte River Ecology Study: U. S. Fish and Wildlife Service Special Scientific Report. Jamestown, North Dakota, USA.

Wheeler, R. H., and J. C. Lewis. 1972. Trapping techniques for sandhill crane studies in the Platte River Valley. U.S. Fish and Wildlife Service Resource Publication 107. Washington D.C., USA.

Williams, G. P. 1978. The Case of the Shrinking Channels-The North Platte and Platte Rivers in Nebraska. U.S. Geological Survey Circular 781, Arlington, Virginia, USA.

Associate Editor: Sheaffer. 